\title{
Environmental Impacts of Waste Management Deficiencies and Health Issues: A Case Study in the City of Kaya, Burkina Faso
}

\author{
Patricia Kafando $^{1}$, Bila Gérard Segda ${ }^{2}$, Jean Fidèle Nzihou ${ }^{3}$, Jean Koulidiati ${ }^{2}$ \\ ${ }^{1}$ Institut de Génie de l'Environnement et du Développement Durable, Université de Ouagadougou, Ouagadougou, Burkina Faso; \\ ${ }^{2}$ Laboratoire de Physique et de Chimie de l'Environnement, Université de Ouagadougou, Ouagadougou, Burkina Faso; ${ }^{3}$ Ecole \\ Normale Supérieure, Université de Koudougou, Koudougou, Burkina Faso. \\ Email: jean_fidele@hotmail.com
}

Received July $9^{\text {th }}, 2013$; revised August $6^{\text {th }}, 2013$; accepted September $12^{\text {th }}, 2013$

Copyright (C) 2013 Patricia Kafando et al. This is an open access article distributed under the Creative Commons Attribution License, which permits unrestricted use, distribution, and reproduction in any medium, provided the original work is properly cited.

\begin{abstract}
In this study, a stratified survey sampling was used in order to broaden our knowledge on the management systems of household waste in the town of Kaya/Burkina Faso. Population study consists of households of the town of Kaya. The sample size was fist determined using the sample size calculation formula. Then four (04) strata comprising the town of Kaya sectors that have a Health and Social Promotion Center (HSPC) have been considered. A random household selection method, used inside each stratum and a number of 468 households representative of the town's population, was surveyed. We have addressed all solid and liquid waste management strategies in those four strata. For each stratum, waste disposal infrastructure, its management in the households and its impacts on the town's environment and populations' health were screened. Data collected are presented through descriptive statistics in mean of tables and graphs. Frequently reported diseases in the four HSPCs have been correlated with waste management and disposal methods in the town. Poor handling, evacuation and disposal of waste have numerous negatives impacts on the city's environment such as proliferation of mosquitoes and flies, bad odors, visual pollution. These negatives impacts on the environment in turn have negatives impacts on the health of the city residents. Malaria appears the most encountered disease followed by Acute Respiratory Infection and Diarrhea. Suggestions aimed at improving waste management and the reduction of its deficiencies impacts on the health of the population has been made.
\end{abstract}

Keywords: Waste Management; Kaya; Environment; Mosquitoes; Sanitation; Malaria; Diarrhea

\section{Introduction}

There is no satisfactory definition of waste, but in Burkina Faso, reference [1] describes municipal waste as "solid, liquid or gas rubbish from the living homes and related, administrative buildings, recreational, restoration and room and any other public installation receiving people". According to [2], in France, waste is defined as "any residue of a process of production, processing or use of any substance, material, product or more generally, any personal property abandoned or which its holder intends to abandon". For environmentalists, waste is an object that can have negative impacts on the environment. The concept of household waste (solid or liquid) means waste from daily household activity. Proper waste management is the set of provisions for the collection, transportation and environmentally sound disposal of waste
[1].

In many countries, the management of waste is sidelined. Meanwhile, pollution transforms the environment into an epidemiologic space [3].

Waste management is one of the major challenges of urban management in Sub Saharan African countries. The current difficulties in the management of solid waste are the result of poor mastering of concepts, approaches and techniques [4].

Just cross some African cities is to see the manifestations of this problem: piles of garbage, trash along roads, landfill blocking riverbeds and threatening health in residential areas, and improper disposal of wastewater.

The town of Kaya, an important center of transit, trade and production including stock breeding and its by-products is no exception to this. Indeed, with urbanization and 
population growth, the city of Kaya produces an enormous amount of waste without adequate infrastructure to manage it. Kaya is the chief town of the province of Sanmatenga. The municipality of Kaya consists of seven (07) sectors and seventy (70) villages over an area of $870.4 \mathrm{~km}^{2}$ [5]. From our field observation, most households are using landfills and other anarchic waste disposal methods that turn street corners or gutters into landfills, making the city insalubrious.

This situation has led us, in the course of our training in the second year of "Master in Planning, Environment and Health", made in the town of Kaya with financial support the NGO Plan Burkina Faso, to assess Environmental impacts of waste management deficiencies and its impacts on the health of population in the city of Kaya.

The overall objective is to study the impacts poor household waste management systems on the environment and the human health, in the city of Kaya.

Specific objectives, are to:

- Study different household waste management systems in the town of Kaya;

- Determine their impact on the environment;

- Determine the impacts of poor waste management on human health;

- Finds correlations between household waste management and the human health;

- Make proposals for better waste management of in the town of Kaya.

The main expected results are:

- An inventory of household waste management systems in the city of Kaya is established;

- The environmental impact of this inadequate management are determined;

- Correlations coefficients between waste management methods and predominant pathologies in the city are calculated;

- Proposals are made for a better management of household waste in the city of Kaya.

\section{Materials and Methods}

\subsection{Study Area}

The city of Kaya, the seventh largest city of Burkina Faso, is located at the North-East of Ouagadougou, Burkina Faso. It is the chef town of the Sanmatenga province and the Central-North region. More specifically this city is situated between coordinates $13^{\circ} 05 \mathrm{~N}$ and $01^{\circ} 05 \mathrm{~W}$ (Figure 1). According to official general population's census, the city of Kaya respectively had 25,814; 33,958 and 54,365 inhabitants in 1985, 1996 and 2006 [6]. For the last two decades, population grown rates of the town are $31.55 \%$ and $60.09 \%$. However waste management facilities are not the priority of the city managers and decision

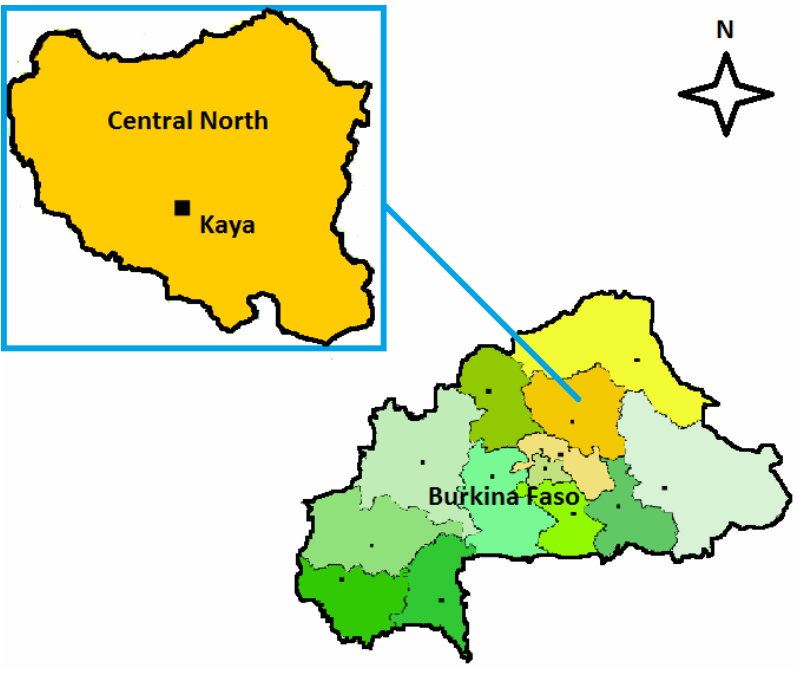

Figure 1. The city of Kaya in the Central-North Region.

makers. With the increase of the population, produced households' waste continues to grow. In lack of structured disposal methods, solid waste are improperly managed by the populations and waste are ultimately thrown into riverbeds, opens spaces, fields or uncontrolled landfills. Wastewater is frequently dumped into streets. This pose significant treats to the environment and the health of populations. The ills of inappropriately disposed municipal waste are quite numerous to be mentioned [7].

\subsection{Type and Context of the Study}

We have implemented an analytical study of waste management systems in the town of Kaya and determined the impact of improper waste management on the environment and human health. The study was conducted in four (04) of the seven (07) geographic and administrative sectors of the city that have a Health and Social Promotion Center (HSPC). These four sectors constitute the four strata of our study. Each stratum has a HSPC in order to better illustrate negatives impacts of poor waste management on health.

\subsection{Variables and Survey Tools}

For a town population grater that 50,000 , we need a representative sample. The minimal sample size in this case is calculated with the following formula [8-11]:

$$
n=\frac{t^{2} \cdot p \cdot(1-p)}{m^{2}}
$$

Where:

$n=$ required sample size

$t=$ confidence level

$p=$ percentage of households picked in the choice, expressed as decimal 


\author{
$m=$ confidence interval or margin error expressed as \\ decimal
}

For surveys of the population $(N)$, we wanted to reach at least $5 \%$ of households $(n)$ in the town. These $n$ household needed to be randomly selected from the four strata of the study area, in order to ensure firstly, the representativeness of results, the reliability of the information resulting from the study and the validity of conclusions, and secondly take into account the time constraint we had.

With a $20 \%$ rate of non participation to the survey, we found $n \geq 400.99$ households. This meant that at least 401 households should be surveyed. We considered a number of 7 persons per household [12] to find the total number of households in the study area. Based on the number of households to be surveyed in each sector (with global coverage rate of $5 \%$ ), we found the number of concessions to visit, taking the average of three concession households (based on our knowledge of the city). These concessions were randomly selected when we accessed each area. We have walked from beginning to end of each in every sector. The questionnaire was administered to an adult in the household selected. During the investigation, we noted the number of households within each concession, which allowed us to quote the number of households actually affected by the survey, in addition to the ten (10) persons responsible for waste management structures we approached. The results are summarized in Table 1. The number of households actually covered by the survey (468) is well greater than the lower limit of 401 .

\subsection{Study Population}

The repartition of the populations between the four strata is as quoted in Table 2.

The targets of the investigation were the sectors 1, 4, 6 and 7 of the city of Kaya and actors of structures involved in the areas covered by the study, namely the City Council, the Provincial Directorate of Environment and Sustainable Development (DPEDD), the Animal Resources

Table 1. Distribution of surveyed households.

\begin{tabular}{cccccc}
\hline Stratum & $\begin{array}{c}\text { NH } \\
\mathrm{a}\end{array}$ & $\begin{array}{c}\text { NHS } \\
\mathrm{b}\end{array}$ & $\begin{array}{c}\text { NCV } \\
\mathrm{c}\end{array}$ & $\begin{array}{c}\text { ANH } \\
\mathrm{d}\end{array}$ & Coverage rate \\
\hline Sector 1 & 2771 & 139 & 47 & 172 & $6.2 \%$ \\
Sector 4 & 1450 & 73 & 25 & 76 & $5.2 \%$ \\
Sector 6 & 2634 & 132 & 44 & 149 & $5.7 \%$ \\
Sector 7 & 2477 & 124 & 42 & 130 & $5.3 \%$ \\
Total & 9332 & 468 & 158 & 527 & \\
\hline
\end{tabular}

a: Number of households; b: Number of households to survey for a $5 \%$ coverage; c: Number of concessions to visit; d: Actual number of households surveyed.
(DPRA), the Agriculture and Water (DPAH), the National Water and Sanitation Office (ONEA), Association for Youth Action and Sustainable Development (AJADD), Centers for Health and Social Promotion (CSPS) in four areas: this was a reasoned choice of the study population.

\section{Results and Discussion}

\subsection{Field Observations}

Our field observations guided the study approach:

1) The lack of infrastructure and waste management facilities, coupled with inappropriate hygiene and sanitation practices in the city of Kaya are a threat to the environment and the health of the population.

2) Carelessly abandoned waste in the city is most likely to expose people to health hazards caused by waste.

3) An effective system of management (collection, treatment and disposal) of waste can contribute to improving the living conditions of populations.

\subsection{Municipal Waste Management at Kaya}

City of Kaya has no data on the quantity (in $\mathrm{kg} / \mathrm{inhab}$, or $\mathrm{m}^{3} /$ day) of waste produced during the three (03) years, but the general consensus is that the production of waste continuously grows with the growing population and economic development. Solid waste produced in the city consists of biodegradable waste (food), paper/cardboard, textiles, metals, scrap, used glasses and batteries. In almost all areas, it is common to see piles of garbage in the streets smelly before the concessions and in the gutters (Figure 2).

Liquid wastes include household's kitchens, dishes, laundry, cleaning, shower grey water; sewage and sludge of latrines. Often wastewater from concessions is stagnating and flowing into streets (Figure 3).

Table 2. Populations by sectors [11].

\begin{tabular}{cccccc}
\hline Sector $(\mathrm{S})$ & S1 & S4 & S6 & S7 & total \\
\hline Population & 19,400 & 10,153 & 18,440 & 17,338 & 65,331 \\
\hline
\end{tabular}

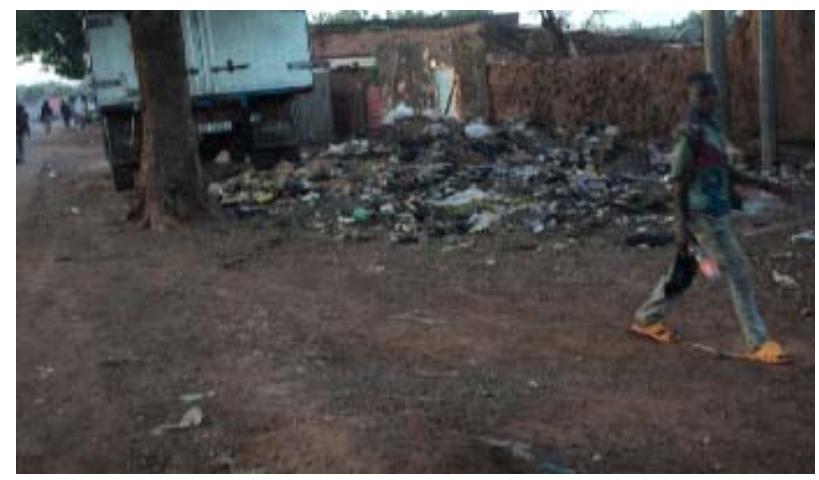

Figure 2. Solid waste pile in front of a concession. 
There are an important number of actors involved in the sanitation or waste management of the city. Unfortunately very few concrete actions are placed on their own in this area of waste management. They all justify the lack of financial and human resources. However, as per their attributions, it is upon them to build, maintain and manage sanitation and waste disposal infrastructures near households and public places all around the city. We also notice the presence of the Youth Association and Action

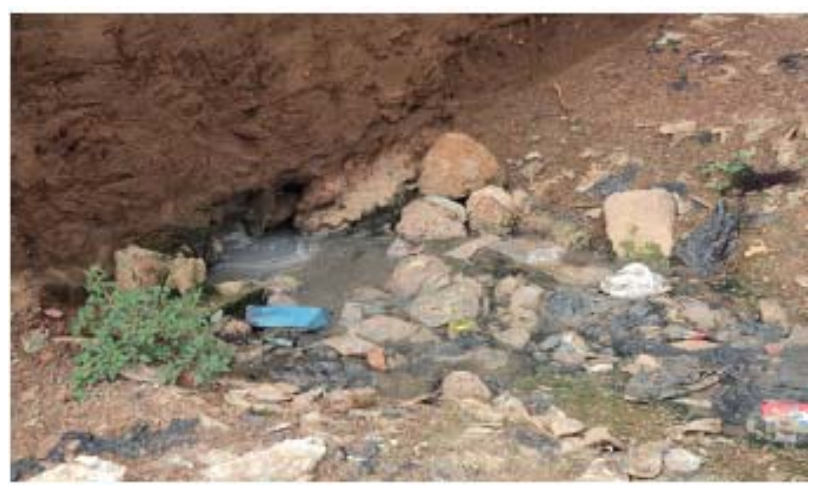

Figure 3. Waste water flowing into a street. for Sustainable Development (AJADD) who take the sanitation of the city as its' his warhorse and received funding for a sorting center that is unfortunately not yet functional. Its activities are also slowed down by its very limited resources. The town of Kaya has a Municipal Development Plan for Water Supply and Sanitation (MDPWSS) $[13,14]$. This is a methodological guide to help the implementation of WSS services that was transferred to Cities Councils in February 2009. Unfortunately the household waste management in the city that is under the responsibility of a single WSS technician $[15,16]$ is not a priority in this WSS plan.

Table 3 shows the current practices in the management of waste. We note that from the number of households surveyed, less than 7\% (most in single household concessions) rent the services of the local association for organized collection of solid waste. There are only an insignificant number of concessions (137 for the whole city) who subscribed to the service of this association. Similarly, very few households (about $32 \%$ ) have soak ways (modern and traditional) for drainage of showers, a required system not separable from other household wastewater disposal systems in the streets.

Table 3. Common pre-collection, collection, evacuation, reuse and disposal of waste by surveyed household.

\begin{tabular}{|c|c|c|c|c|c|c|c|c|c|}
\hline \multirow{2}{*}{\multicolumn{2}{|c|}{ Modalities }} & \multicolumn{2}{|c|}{ Sector 1 (47) } & \multicolumn{2}{|c|}{ Sector 4 (25) } & \multicolumn{2}{|c|}{ Sector 6 (44) } & \multicolumn{2}{|c|}{ Sector 7 (42) } \\
\hline & & $\mathrm{Num}^{\mathrm{a}}$ & Freq. $^{\mathrm{b}}$ & Num & Freq. & Nom & Freq. & Num & Freq. \\
\hline \multirow{4}{*}{$\begin{array}{l}\text { Pre collection (stocking at the production site) } \\
\text { of solid municipal waste (SMW) }\end{array}$} & Used bins & 34 & $72 \%$ & 13 & $52 \%$ & 31 & $71 \%$ & 40 & $95 \%$ \\
\hline & Half barrel & 2 & $4 \%$ & 8 & $32 \%$ & 1 & $2 \%$ & 0 & $0 \%$ \\
\hline & Cement tank & 6 & $13 \%$ & 2 & $8 \%$ & 0 & $0 \%$ & 0 & $0 \%$ \\
\hline & Ground (inside/in front of households ) & 5 & $11 \%$ & 2 & $8 \%$ & 12 & $27 \%$ & 2 & $5 \%$ \\
\hline \multirow{2}{*}{ SMW collection } & Organized & 2 & $4 \%$ & 8 & $32 \%$ & 1 & $2 \%$ & 0 & $0 \%$ \\
\hline & Non organized & 45 & $96 \%$ & 17 & $68 \%$ & 43 & $98 \%$ & 42 & $100 \%$ \\
\hline \multirow{4}{*}{ Evacuation (landfilling) of SMW } & Excavations & 0 & $0 \%$ & 0 & $0 \%$ & 1 & $2 \%$ & 10 & $24 \%$ \\
\hline & Gutters & 10 & $22 \%$ & 2 & $12 \%$ & 0 & $0 \%$ & 4 & $10 \%$ \\
\hline & Fields & 23 & $51 \%$ & 7 & $41 \%$ & 32 & $75 \%$ & 11 & $26 \%$ \\
\hline & Empty spaces & 12 & $27 \%$ & 8 & $47 \%$ & 10 & $23 \%$ & 17 & $40 \%$ \\
\hline \multirow{4}{*}{ Wastewater disposal } & Inside concessions & 3 & $7 \%$ & 0 & $0 \%$ & 12 & $27 \%$ & 2 & $5 \%$ \\
\hline & Into gutters & 6 & $13 \%$ & 7 & $28 \%$ & 0 & $0 \%$ & 0 & $0 \%$ \\
\hline & Into cesspits & 11 & $23 \%$ & 13 & $52 \%$ & 9 & $21 \%$ & 17 & $40 \%$ \\
\hline & In streets & 27 & $57 \%$ & 5 & $20 \%$ & 23 & $52 \%$ & 23 & $55 \%$ \\
\hline \multirow{2}{*}{ Draining of latrines and/or cesspits } & Manual & 30 & $64 \%$ & 14 & $56 \%$ & 37 & $84 \%$ & 40 & $95 \%$ \\
\hline & Mechanical (tanker) & 17 & $36 \%$ & 11 & $44 \%$ & 7 & $16 \%$ & 2 & $5 \%$ \\
\hline \multirow{3}{*}{ Elimination/Reuse of SMW } & Composting & 33 & $73 \%$ & 14 & $82 \%$ & 39 & $91 \%$ & 27 & $64 \%$ \\
\hline & Incineration & 2 & $5 \%$ & 2 & $12 \%$ & 1 & $02 \%$ & 10 & $24 \%$ \\
\hline & Food for animals (sheep and pigs) & 20 & $44 \%$ & 7 & $41 \%$ & 18 & $42 \%$ & 12 & $29 \%$ \\
\hline
\end{tabular}

${ }^{\mathrm{a}} \mathrm{Num}=$ number; ${ }^{\mathrm{b}}$ Freq. $=$ frequency. 
Since several years, fifty cement garbage bins brick were built in some areas of the city. In today's date, fewer than a dozen of these tanks still exist and the amount of waste generated exceeds their volume $\left(10 \mathrm{~m}^{3}\right)$. When these containers are full, the waste is either burned on the spot or sent to landfill. Three metal trash bins are arranged around the central market by the City Council who is also responsible for their evacuation. Here again, the bins are poorly used, there is always waste sitting at the ground, even when bins are not full. The town of Kaya has no controlled landfill (only three allowed transfer sites), the final destination of solid waste being the fields of population and uncontrolled landfills away from homes. Similarly, there is no adequate system for the treatment and disposal of household wastewater.

This is the origin of various immediate impacts (short term) or delayed (for storage/long term) or by substances that disrupt the ecological balance of the environment, or by toxic substances beings alive.

At Kaya, the management system does not include waste treatment, but directly land filling and/or incineration. Yet these practices have proven bearing potential negative impact on the environment and health [17].

According to health statistics from the four HSPC in the study area, three (03) diseases, namely Malaria, Acute respiratory infections and diarrhea are the most common pathologies in the city (Figure 4).

Table 4 give us calculated Person's correlations coefficients (PCCs) between household waste management and disposal methods and the predominant pathologies in four HSPC at Kaya. Although high PCCs values don't necessarily imply a causal link between two parameters [18], these can still suggest that two parameters have a common cause. Collecting waste in used bins or half barrel seems to promote the proliferation of mosquitoes and flies, which are known as malaria and diarrhea vectors (Person's coefficients equal to 0.62 and 0.83 ). In contrast waste collection in tanks seems to reduce the incidence of ARI and diarrhea. The explanation is that this put more away these diseases vectors. Malaria and diarrhea seems also linked to waste disposal into empty spaces (PPCs equal to 0.8). The same seem true for manual sewage of latrines and sumps. ARIs exhibit negatives Person's coefficients in respect of all waste disposal methods. This seems suggesting that ARIs decrease in respect of all waste disposal methods. This sound confusing, but bad waste disposal result to odor annoying (gazes sources of ARIs), population push these smelly waste far away, thus the apparent decrease of ARIs.

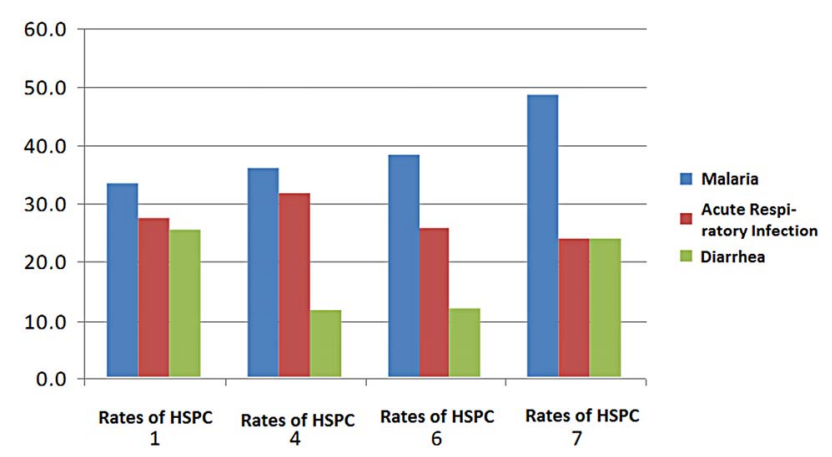

Figure 4. Proportions of the 3 predominant pathologies in the 4 HSPC of Kaya.

Table 4. Correlation coefficients between waste disposal methods and the three most encountered pathologies in the city of Kaya.

\begin{tabular}{|c|c|c|c|c|c|}
\hline & & Malaria & $\mathrm{ARI}^{\mathrm{a}}$ & Diarrhea & Remarks \\
\hline \multirow[b]{2}{*}{ Households solide waste precollection tool } & Used bin & 0.63 & -0.93 & 0.77 & Humidity: mosquitoes;odors; flies \\
\hline & Used bin or Barrel & 0.62 & -0.89 & 0.83 & Humidity: mosquitoes;odors; flies \\
\hline \multirow{2}{*}{ Households solide waste collection } & Organized & -0.64 & 0.98 & -0.59 & Not statisticaly meaningful \\
\hline & Unorganized & 0.37 & -0.87 & 0.64 & Odors \\
\hline \multirow{3}{*}{ Households solide waste disposal method } & Excavations or Gutters & 0.51 & -0.50 & 0.94 & Stagnant water: flies \\
\hline & Fields & -0.12 & -0.48 & -0.05 & No correlation \\
\hline & Empty spaces & 0.80 & -0.76 & 0.80 & Stagnant water: mosquitoes, odors, flies \\
\hline \multirow{3}{*}{ Waste water disposal place } & Concessions or Gutters & 0.04 & -0.68 & 0.43 & Odors \\
\hline & Cesspools & 0.64 & -0.14 & 0.44 & Stagnant water: mosquitoes \\
\hline & Streets & 0.30 & -0.83 & 0.69 & Proliferation of flies, odors \\
\hline Sewage of latrines and sumps & Manual & 0.73 & -1.00 & 0.50 & Stagnant water: mosquitoes, odors \\
\hline \multirow{3}{*}{$\begin{array}{l}\text { Incineration and valorisation of solid household } \\
\text { waste }\end{array}$} & Composting & 0.17 & -0.75 & 0.25 & Gazes release from composting \\
\hline & Incineration & 0.85 & -0.52 & 0.57 & Not statisticaly meaningful \\
\hline & Animals breeding & -0.13 & -0.54 & 0.41 & No correlation \\
\hline
\end{tabular}

${ }^{\mathrm{a}} \mathrm{ARI}=$ Acute Respiratory Infections. 


\subsection{Impacts of Inappropriate Household Waste Management on the Environment}

The current situation of the environment in the town of Kaya is closely related to the current situation of waste management. The decomposition of solid waste in landfills (organic elements they contain) under the action of water, air and the temperature is likely to cause immediate or distant incalculable dangers to the environment of the man (pollution, odors ${ }^{\cdots}$ ). Liquid wastes are also significant dangers to the environment including pollution of soil, water and air. Some waste pollutants (heavy metals and hydrocarbons) are likely to accumulate in wildlife, flora and in the food chain $[19,20]$.

- Soil pollution: Stagnation and the infiltration of wastewater are factors that influence the degradation of components of the environment (ecosystem degradation). Plastic bags waste and are especially a permanent danger to natural resources and animals. Plastic is a non-biodegradable material. Poorly managed, plastic bags pollute the soil, attack vegetation, reduce infiltration of rainwater, clogged pipes and drains discharge storm water and wastewater.

- Air pollution: Discharging, methane, abundantly generated by the decomposition of organic matter contributes significantly to the greenhouse effect and is explosive in certain concentrations. According to reference [4], there is the formation of a biogas in landfills containing about $40 \%$ to $60 \%$ of methane (the remainder being carbon dioxide, nitrogen, hydrogen sulfide, and various acids or more less volatile and sulfur). Open air waste firing that may appear as an attractive solution for waste management (because it allow reduction volumes reduction rates of $75 \%$ to $90 \%$ ), contributes to the production of flying heavy metals particulates and hydrochloric acid known as very dangerous pollutants. Combustion of one ton of municipal waste results in the release of more than $7 \mathrm{~kg}$ of hydrochloric acid.

- Water pollution: household waste and their soil infiltration pollute groundwater. Solid waste and domestic sewage sludge are rich in organic waste, fats (cooking water), mineral substances (water bath, laundry), hydro carbonates, nitrogen, phosphorus and potassium (toilets sewage flush), carried materials in suspension which pollute the water. According to the head of the grouping center of ONEA at Kaya, "failure in achieving standards of sanitation in individual sanitation facilities is a pollution source of ground and surface water resources, with the risk of pollution of the water supply network". This is evidenced by the abandonment of drilling water exploitation by ONEA because of contamination, and much degraded quality of raw water treatment plant during the rainy season. Therefore water supply for the town Kaya by ONEA is now secured from the Dem Lake [21]. There is also the siltation of rivers due to high turbidity induced by suspended materials and increased consumption of dissolved oxygen by the supplementary and abundant organic matter.

\subsection{Human Health Impacts of Inappropriate Household Waste Management}

Health issues related to waste are complex and gives rise to numerous debates [22]. Given the diversity of pollutants present, management methods and routes of exposure, knowledge remains imperfect and still need to be improved. We are only considering these issues on an environmental engineering point of view. No epidemiological study has been done. From our survey, all targets authors agree on the fact that the mismanagement of waste has enormous impacts on human health. Although most of them criminalize stagnant wastewater and excreta, there are those who have noticed the impact of solid waste in putrefaction and toxics waste.

Water is a natural resource essential to the life. But in an unhealthy environment, water becomes directly or indirectly a cause of illness or death. Mismanagement of waste causes pollution of groundwater. This contaminated water from wells is not treated according to the hygiene standards but is still consumed by people in the town.

Wastewater stagnation and infiltration, lack of maintenance and failures of sanitation facilities causes more pollution and proliferation of disease vectors (malaria, diarrhea, cholera, amoebiasis $\cdots)$. According to [4], all pollutants from waste incineration can be transmitted both by direct-inhalation and skin contact with pollutants, and by indirect means.

Airborne dust affect the respiratory and cardiovascular volatile organic compounds ranging from odor annoyance to the carcinogenic effects; hydrochloric acid is a potential irritant to skin, eyes and respiratory tract, causing respiratory and cardiovascular diseases and cancer.

\subsection{Proposals for Better Waste Management in the City of Kaya}

In our study, we found that inadequate management of waste induces the degradation of the living environment and human health. In addition, much of the city's populations still does not measure these impacts and justifies their bad practices by lack financial assets as a major factor in their poor management of waste.

For batter management of waste in order to improve the life quality of the inhabitants of the town of Kaya, we suggest to local authorities and development actors:

- Strengthen information, education and communication (IEC) of the population on the impacts of poor waste management in through broadcasting/debates, 
door to door sensitization, forum theater, movies projections followed by discussion $\cdots$ for awareness and a real change in individual and collective behavior;

- Conduct, promote and maintain the household waste management infrastructure (garbage bins, controlled landfills, latrines and cesspools, improved reliability drainage, mini sewage $\cdots$ );

- Organize and fund the collection and sorting, transport and treatment of waste;

- Write or revise texts of adequate waste management (with the roles and responsibilities of each actor) and implement them in a synergy of actions;

- Strengthen the capacity of the actors in the management of waste, namely the AJADD through training, equipment, educational movies, audio-visual kits, sanitation and Personal Protective Equipment (glasses, boots, gloves, coat, dust mask, rakes, shovels, brooms ${ }^{\cdots}$ ).

We noted the scarcity of bottles (glass and plastic) and scrap in dumpsters and landfills because these are much foreseen and do enter in a recycle/reuse circuit. Therefore, we propose that the emphasis be done on waste recycling options, for example through:

- the transformation of paper/cardboard sticks into fuels used for cooking,

- grinding of hard plastic that can be sold at the Fasoplast factory,

- melting and mixing plastic bags with fine sand for making pavers. This technique is increasingly used for paving the streets in the town of Kaya.

- transforming aluminum into dishes,

- converting biodegradable waste into compost for the fields, thus reducing the use of some chemical fertileizers harmful to human health.

\section{Conclusions}

The situation of poor waste management in the town of Kaya is at one side the responsibility of the authorities because they have to set up appropriate infrastructure and drainage facilities, proceeds to or delegates the collection and treatment of household waste. At the other side this situation results from bad practices of populations which lead to the proliferation of uncontrolled solid waste land filling and stagnant wastewater through the town of Kaya.

It turned out that the abandonment of waste carelessly in the city practice is most likely to expose people to health hazards caused by waste. A household waste collection and treatment system with more recycling or reuse and disposal of household waste at Kaya and its immediate vicinity, would induce significant progress in terms of urban development, but also would be a big step for sanitation the city, public health and environmental protection.
Our limited resources and the time allotted for the internship could lead to deficiencies in this study. Nevertheless, foundations laid here should help for future researches and further investigation of the issues related to inappropriate waste disposal method effects on the environment and health. It would also help find sustainable solutions to this matter. Under this scope, a waste characterization of the city in order to know the quantity, quality and hazardous nature among others would be foreseen.

\section{REFERENCES}

[1] Assembly of People's Deputies, “Act N ${ }^{\circ}$ 005/97/ADP on the Environmental Code in Burkina Faso," In French, 1997.

[2] French National Assembly, "Environmental Code, Act Art. L.541-1," In French, 1975.

http://www.legifrance.gouv.fr/

[3] ENDA-Tiers Monde, "Waste and Human: Experiences of Recycling in the Third World," In French, ENDA-Tiers Monde, Dakar, 1990, 300 p.

[4] Alabater, "Waste Minimization Strategies for Developing Countries," SIEP/UNCHS, Ittingen Workshop, UMP/ SDC, Collaborative Program on Municipal Solid Waste in Low Incomes Countries, 1995.

[5] Ministry of Economics and Finances, Burkina Faso, "Socio Economic Dashboard of the Central-North Region," In French, 2011.

http://www.finances.gov.bf/files/Donnees_socio_economi ques/Tableau de_Bord_Socio-Economique Centre-Nord. pdf

[6] National Institute for Statiscs and Demography, "The Central-North Region in Figures,” In French, 2011. http://cns.bf/IMG/pdf/centrenord_2010_vf_ok-2.pdf

[7] F. Sankoh, X. Yan and T. Yen, "Environmental and Health Impact of Solid Waste Disposal in Developing Cities: A Case Study of Granville Brook Dumpsite, Freetown, Sierra Leone," Journal of Environmental Protection, Vol. 4, No. 7, 2013, pp. 665-670.

http://dx.doi.org/10.4236/jep.2013.47076

[8] B. Godden, "Sample Size Formulas," 2004. http://williamgodden.com/samplesizeformula.pdf

[9] G. D. Israel, "Determining Sample Size," Department of Agricultural Education and Communication, Institute of Food and Agricultural Sciences (IFAS), University of Florida, Gainesville, 1992. http://edis.ifas.ufl.edu/pdffiles/PD/PD00600.pdf

[10] S. Ahmed, "Methods in Sample Surveys," Department School of Hygiene and Public Health, Johns Hopkins University, 2009.

http://ocw.jhsph.edu/courses/statmethodsforsamplesurvey s/PDFs/Lecture2.pdf

[11] International Fund for Agricultural Development, "Calculating the Sample Size."

http://www.ifad.org/gender/tools/hfs/anthropometry/ant_ 
3.htm

[12] National Institute for Statistics and Demography, "Statistical Handbook of the Central-North Region, Year 2008," In French, 2011. http://cns.bf/IMG/pdf/annuaire_centre_nord.pdf

[13] City of Kaya, "Water Supply and Sanitation - Communal Sector Development Plan (WSS-CDP)," In French, ANTEA/ SAPAD Group (Burkina-Faso), City of Kaya, 2010, 70 p.

[14] Ministry of Agriculture, Water Resources and Fisheries/ National Program for Water Supply and Sanitation, "Regional Sector Report. Annual Balance Sheet at December 31, 2010," In French, 2010. http://www.eauburkina.org/PN-AEPA/documents/

[15] House of Decentralized Cooperation, "Drinking Water and Sanitation Supply Program for Nine Towns of Burkina Faso-Information Note n ${ }^{\circ}$ 5, February, 2013,” 2013. http:/www.mcdburkina.bf/projets_programmes/rapports/ NOTE_INFORMATION_N05.pdf

[16] House of Decentralized Cooperation, "Drinking Water and Sanitation Supply Program for nine towns of Burkina Faso-Information Note $n^{\circ}$ 5, March, 2013,” 2013. http://www.mcdburkina.bf/projets programmes/rapports/ NOTE_INFORMATION_N06.pdf

[17] National High Polytechnic School, "Management and Use of Wastewater in Areas of Planned Habitat and Their Peripheries," Sanitation A08, Final Report, 2003, 167 p.
http://www.pseau.org/epa/gdda/Actions/Action_A08/Rap port_final_A08.pdf

[18] R. Taylor, "Interpretation of the Correlation Coefficient: A Basic Review," Journal of Diagnostic Medical Sonnography, Vol. 6, No. 1, 1990, pp. 35-39. http://dx.doi.org/10.1177/875647939000600106

[19] N. J. G. J. Bandara and P. J. Hettiarachchi "Environmental Impacts Associated with Current Waste Disposal Practices in a Municipality in Sri Lanka-A Case Study," Workshop on Sustainable Landfill Management, Chennai, 3-5 December 2003, pp. 19-26.

[20] S. Abul, "Environmental and Health Impact of Solid Waste Disposal at Mangwaneni Dumpsite in Manzini: Swaziland," Journal of Sustainable Development in Africa, Vol. 12, No. 7, 2010, pp. 64-78.

[21] ONEA, "The Works of the Water Supply at Kaya Are completed," In French, 2009. http://www.oneabf.com/a-la-une/actualites/85-les-travaux -de-laep-kaya-sont-acheves.html

[22] Department for Environment, Food and Rural Affairs, "Review of Environmental and Health Effects of Waste Management: Municipal Solid Waste and Similar Wastes," Queen's Printer and Controller of HMSO, 2004. http://archive.defra.gov.uk/environment/waste/statistics/d ocuments/health-summary.pdf 